- This manuscript is the first attempt to investigate potential links between dental treatment and the development of VCJD using case control methodology.

- The results highlight difficulties in collecting retrospective data from relatives of CJD cases regarding dental treatment history.

- Access to case and control dental records in the future may provide more useful information.

\title{
Dental treatment and risk of variant CJD - a case control study
}

\author{
D. Everington, ${ }^{1}$ A. J. Smith, ${ }^{2}$ H. J. T. Ward, ${ }^{3}$ S. Letters, ${ }^{4}$ R. G. Will ${ }^{5}$ and J. Bagg ${ }^{6}$
}

\begin{abstract}
Objective Knowledge of risk factors for variant CJD (VCJD) remains limited, but transmission of prion proteins via re-useable medical devices, including dental instruments, or enhanced susceptibility following trauma to the oral cavity is a concern. This study aimed to identify whether previous dental treatment is a risk factor for development of VCJD.

Design Case control study.

Methods Risk factor questionnaires completed by interview with relatives of $130 \mathrm{VCJD}$ patients and with relatives of 66 community and 53 hospital controls were examined by a dental surgeon. Responses regarding dental treatments were analysed.

Results We did not find a statistically significant excess of risk of VCJD associated with dental treatments with the exception of extractions in an unmatched analysis of VCJD cases with community controls $(p=0.02)$. However, this result may be explained by multiple testing. Conclusions This is the first published study to date to examine potential links between VCJD and dental treatment. There was no convincing evidence found of an increased risk of variant CJD associated with reported dental treatment. However, the power of the study is restricted by the number of VCJD cases to date and does not preclude the possibility that some cases have resulted from secondary transmission via dental procedures. Due to the limitations of the data available, more detailed analyses of dental records are required to fully exclude the possibility of transmission via dental treatment.
\end{abstract}

Statistician, National Creutzfeldt-Jakob Disease Surveillance Unit, The University of Edinburgh, Western General Hospital, Crewe Road, Edinburgh, EH4 2XU; ${ }^{2 *}$ Senior Lecturer in Microbiology, Infection Research Group, University of Glasgow Dental School, 378 Sauchiehall Street, Glasgow, G2 3JZ; ${ }^{3}$ Consultant Epidemiologist, National Creutzfeldt-Jakob Disease Surveillance Unit, The University of Edinburgh, Western General Hospital, Crewe Road, Edinburgh, EH4 2XU; ${ }^{4}$ Visiting General Dental Practitioner, Infection Research Group, University of Glasgow Dental School, 378 Sauchiehall Street, Glasgow, G2 3JZ; ${ }^{5}$ Professor of Clinical Neurology, National Creutzfeldt-Jakob Disease Surveillance Unit, The University of Edinburgh, Western General Hospital, Crewe Road, Edinburgh, EH4 2XU; ${ }^{6}$ Professor of Clinical Microbiology, Infection Research Group, University of Glasgow Dental School, 378 Sauchiehall Street, Glasgow, G2 3JZ *Correspondence to: Dr Andrew J. Smith

Email:a.smith@dental.gla.ac.uk

\section{Online article number E19}

Refereed Paper - accepted 11 May 2006

DOI: $10.1038 /$ bdj.2007.126

${ }^{\circ}$ British Dental Journal 2007; 202: E19

\section{INTRODUCTION}

Variant CJD (vCJD) differs from other forms of CJD in that abnormal prion protein and probably infectivity are consistently found outside the central nervous system. A risk assessment for VCJD and dentistry estimated that the risk of transmission of vCJD from dental instruments was low provided decontamination procedures were not significantly less effective than previously assumed. ${ }^{1}$ There is a potential for onward transmission of VCJD via re-usable medical devices and difficulties in sterilisation of some dental instruments, for example endodontic files ${ }^{2}$ and matrix bands, ${ }^{3}$ which has led to continued concerns about the possibility of secondary transmission of vCJD through dental procedures. Furthermore, the results of a National survey of decontamination in general dental practice in the UK has demonstrated widespread shortcomings in decontamination practice. ${ }^{4}$ Although the disease-associated form of prion protein has been found using bioassays in trigeminal ganglion, pulpal tissue and gingival tissue in a hamster model, ${ }^{5}$ and in tongue in a mink model, ${ }^{6,7}$ studies in $\mathrm{vCJD}^{8}$ and sporadic $\mathrm{CJD}^{9}$ using immunohistochemistry techniques have been negative. However, despite negative immuno-staining and transmission studies in blood from vCJD cases, it has now been found that vCJD infection can be transmitted by blood transfusion. ${ }^{10,11}$ It is important to examine the evidence from the natural disease for all potential risk factors including those where the presumed risk is relatively low. Previous case control studies in sporadic CJD ${ }^{12,13}$ have not identified dental treatment as a risk factor. This paper describes an analysis of reported dental treatment undergone by cases of VCJD compared with community and hospital controls.

\section{MATERIALS AND METHODS}

Variant CJD cases were reported to the National CreutzfeldtJakob Disease Surveillance Unit (NCJDSU), Edinburgh. ${ }^{14}$ Ethical approval was obtained from a multi-centre research ethics approval committee. Information on potential risk 
factors, including dental treatment, was obtained for each patient through face-to-face interview with relatives using a standardised questionnaire. For each case, attempts were made to recruit controls from two different groups - community (up to four per case) and hospital controls (one per case). Community controls were randomly selected individuals registered with the same general medical practice as cases, matched by sex and age $+/-4$ years. Hospital controls were individuals with non-neurological diagnoses, randomly selected from another ward in the same hospital as the case and matched to cases by sex and age $+/-4$ years.

As for cases, face-to-face interviews using a standardised risk factor questionnaire with relatives of controls were carried out. Relatives were asked 'Since the beginning of 1980 has the subject (case or control) received dental treatment other than fillings, for example extractions or root canal work?' A description of such treatment with dates was sought.

A dental practitioner (SL) performed a review of relatives' responses for cases and controls. The dental practitioner categorised the treatments and ordered them in terms of risk of prion transmission prior to data analysis. Based on current published data the highest risk tissue for transmission of vCJD in the oropharynx is the lingual and tonsillar lymphoid tissue. However, this is unlikely to be traumatised during routine dental treatment. ${ }^{1}$ Lower risks of transmission associated with dental treatment were ranked on the basis of degree of invasiveness, tissues contacted and the 'cleanability' of the instruments used (presence of lumens, connectors etc). Root canal treatment was judged as highest risk on the grounds that endodontic instruments are difficult to clean and are frequently in direct contact with the neurovascular tissues in dental pulp. ${ }^{2}$ Dental extractions were considered the second highest risk, followed by crown and bridge work.

\section{STATISTICAL ANALYSIS}

Logistic regression and conditional logistic regression (Stata Statistical Software) was used to examine differences between dental histories of the cases and controls for the unmatched and matched analyses respectively.

The frequency of treatments other than root canal treatment, extractions and crowns/bridges was too low for meaningful analysis. The following six putative risk factors were, therefore, analysed: (1) root canal treatment (identified a priori as the highest risk treatment); (2) extractions (identified a priori as the second highest risk treatment); (3) crowns/bridges; (4) root canal treatment or extractions; (5) root canal treatment, extractions or crowns/bridges; and (6) any dental treatment.

\section{RESULTS}

The case-control study has been in operation since the first case of vCJD was identified in 1996 and almost all the families of cases (98\%) have agreed to take part in the study. There were 159 vCJD cases reported by 31 December 2005; with 156 vCJD cases recruited to the case control study. Twenty-six cases were excluded from the study because early in the study information on dental treatment was only requested for the previous year. For the 130 cases of vCJD in this study, 66 had community control data and 53 had hospital control data.

Table 1 shows the frequency of dental treatments undertaken by vCJD cases and hospital and community controls. Frequencies of specific treatments were broadly similar between cases and both control groups, except for an excess of dental extractions seen in vCJD cases compared to community controls ( $\mathrm{p}=$ 0.02). No other comparison was significant at the 5\% level.

Results from the matched analyses of cases and controls are shown in Table 2. Of 66 cases, 25 were matched with one community control, 10 with two controls, 20 with three

Table 1 Dental treatment procedures reported for cases and controls

\begin{tabular}{l|l|l|l}
\hline Treatment & Number of cases $(n=130)$ & $\begin{array}{l}\text { Number of community controls } \\
(\mathrm{n}=149)\end{array}$ & $\begin{array}{l}\text { Number of hospital controls } \\
(\mathrm{n}=53)\end{array}$ \\
\hline Any dental treatment & $64(49 \%)$ & $59(40 \%)$ & $31(58 \%)$ \\
\hline Root canal treatment & $8(6 \%)$ & $9(6 \%)$ & $1(2 \%)$ \\
\hline Extractions & $51(39 \%)$ & $39(26 \%)$ & $22(42 \%)$ \\
\hline Crowns or bridges & $8(6 \%)$ & $13(9 \%)$ & $6(11 \%)$ \\
\hline Root canal treatment or extractions & $56(43 \%)$ & $48(32 \%)$ & $23(43 \%)$ \\
\hline $\begin{array}{l}\text { Root canal treatment, extractions, } \\
\text { crown or bridge work }\end{array}$ & $61(47 \%)$ & $57(38 \%)$ & $29(55 \%)$ \\
\hline Dentures or orthodontics & $7(5 \%)$ & $2(1 \%)$ & $2(4 \%)$ \\
\hline
\end{tabular}

Table 2 Comparison of reported dental treatment procedures, categorised by risk, between cases and controls

\begin{tabular}{|c|c|c|c|c|}
\hline \multirow{2}{*}{ Putative risk factor } & \multicolumn{2}{|c|}{$\begin{array}{l}\text { Cases }(n=66) \text { vs community controls } \\
(n=149)\end{array}$} & \multicolumn{2}{|c|}{$\begin{array}{l}\text { Cases }(n=53) \text { vs hospital controls } \\
(n=53)\end{array}$} \\
\hline & $\mathrm{OR}$ & $95 \% \mathrm{Cl}$ & $\mathrm{OR}$ & $95 \% \mathrm{Cl}$ \\
\hline $\begin{array}{l}\text { Any dental treatment } \\
\text { Root canal treatment (RCT) }\end{array}$ & $\begin{array}{l}1.5 \\
1.3\end{array}$ & $\begin{array}{l}0.8,2.6 \\
0.4,4.3\end{array}$ & $\begin{array}{l}0.6 \\
3.0\end{array}$ & $\begin{array}{l}0.3,1.3 \\
0.3,28.8\end{array}$ \\
\hline $\begin{array}{l}\text { Extractions } \\
\text { Crowns or bridges } \\
\text { RCT or extractions }\end{array}$ & $\begin{array}{l}1.7 \\
0.4 \\
1.6\end{array}$ & $\begin{array}{l}0.9,3.2 \\
0.1,2.0 \\
0.9,3.1\end{array}$ & $\begin{array}{l}0.7 \\
0.7 \\
0.8\end{array}$ & $\begin{array}{l}0.3,1.6 \\
0.2,2.4 \\
0.4,1.7\end{array}$ \\
\hline $\mathrm{RCT}$, extractions, crown or bridge work & 1.4 & $0.8,2.5$ & 0.7 & $0.3,1.4$ \\
\hline
\end{tabular}


controls and 11 with four controls. Analysis of hospital controls matched to cases was based on 53 cases matched with one hospital control. These data do not provide convincing evidence of increased risk associated with reported dental treatments categorised a priori according to potential risk of vCJD transmission.

\section{DISCUSSION}

Many studies have searched for risk factors for the development of different types of CJD, such as diet, exposure to animals, surgical treatment, including dentistry, and occupational exposures. A retrospective case control study ${ }^{15}$ of 60 definite cases of sporadic CJD, occurring in Japan between 1975 and 1977 found no association with extractions of maxillary or mandibular teeth. An analysis of 26 sporadic CJD cases and 40 matched controls from the United States ${ }^{16}$ failed to discover a significant odds ratio for endodontic surgery, though these workers did note statistically significant odds ratios for intraocular pressure testing, injury to or surgery on the head, face or neck and trauma to other parts of the body. However, these findings suffer from low statistical power and, in the case of the Japanese paper, information was requested for extractions only during the five year period prior to onset. This paper attempts to identify an association between vCJD and reported dental treatment.

Comparison of the reported dental histories of cases and controls found that extractions were the only dental risk factor that reached statistical significance (at the 5\% level) in the unmatched analysis with community controls. This may be a result of multiple testing especially as there are fewer extractions in the cases than in the hospital controls. It is likely that the majority of vCJD cases in this cohort were infected through eating BSE contaminated meat products. Therefore, it is difficult to detect a small subgroup that may have been infected by secondary transmission, as in this study, through dentistry.

There are a number of limitations to this study, most importantly relying on reported data from relatives and the relatively small numbers of cases and controls resulting in low power to detect statistical differences. Recruitment of controls has been problematic, ${ }^{17}$ although every effort was made to maximise this group. Selection of controls was not matched for demographic and socio-economic factors for dental attendance and this may have resulted in bias. It is possible that some of the responses of 'no known treatment' reflect poor knowledge or recall on the part of the relatives. This would reduce the power of the study to pick up significant differences between groups, but not necessarily introduce bias.

Whilst these preliminary data on a topic of great concern for public health do not provide evidence supporting reported dental work as being a major route of transmission of the BSE agent to humans to date, they do not preclude the possibility that some vCJD cases have been infected by this route. Furthermore, the incubation period following infection by a peripheral route may be relatively long and therefore the period of observation to date of potential secondary transmission of vCJD may be too short to detect cases.

A more detailed study of previous treatment based on reviewing actual dental records rather than relying on reported treatments is required to gain a wider insight into the dental history of both cases and controls. We are currently investigating the possibility of examining dental records of vCJD cases and a larger group of unmatched controls. ${ }^{18}$

The National CJD Surveillance Unit is funded by the Department of Health and the Scottish Executive Department of Health. The sponsors of the study had no role in study design, data collection, data analysis, data interpretation, or in the writing of the report. We are also grateful to the families of cases, without whose co-operation this study would not have been possible.

1. Department of Health Economics and Operational Research Division. Risk assessment for VCJD and dentistry. London: The Stationery Office, 2003

(www.doh.gov.uk/cjd/dentistryrisk/index.htm).

2. Smith A J, Bagg J, Aitken J, Dickson M. Contaminated dental instruments. J Hosp Infect 2002; 51: 233-235.

3. Lowe A H, Bagg J, Burke F J T, MacKenzie D, McHugh S. A study of blood contamination of Siqveland matrix bands. Br Dent J 2001; 192: 43-45.

4. NHS Scotland Sterile Services Provision Review Group. Survey of decontamination in general dental practice. Edinburgh: The Stationery Office; 2004 (www.scotland.gov.uk/library5/health/sdgdp-00.asp).

5. Ingrosso L, Pisani F, Pocchiari M. Transmission of the $263 \mathrm{~K}$ scrapie strain by the dental route. J Gen Virol 1999; 80: 3043-3047.

6. Bartz J C, Kincaid A E, Bessen R A. Rapid prion neuroinvasion following tongue infection. J Virol 2003; 77: 583-591.

7. Mulcahy E R, Bartz J C, Kincaid A E, Bessen R A. Prion infection of skeletal muscle cells and papillae in the tongue. J Viro/ 2004; 78: 6792-6798.

8. Head M W, Ritchie D, McLoughlin V, Ironside J W. Investigation of PrPres in dental tissues in variant CJD. Br Dent J 2003; 195: 339-343.

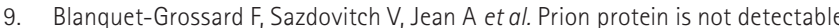
in dental pulp from patients with Creutzfeldt-Jakob disease. J Dent Res 2000; 79: 700 .

10. Llewelyn C A, Hewitt P E, Knight R S G et al. Possible transmission of variant Creutzfeldt-Jakob disease by blood transfusion. Lancet 2004; 363: 417-421.

11. Peden A H, Head M W, Ritchie D L, Bell J E, Ironside J W. Preclinical vCJD after blood transfusion in a PRNP codon 129 heterozygous patient. Lancet 2004; 264: 527-529.

12. Van Duijn C M, Delasnerie-Laupretre N, Masullo C et al. Case-control study of risk factors of Creutzfeldt-Jakob disease in Europe during 1993-95. Lancet 1998; 351: 1081-1085.

13. Collins S, Law M G, Fletcher A, Boyd A, Kaldor J, Masters C L. Surgical treatment and risk of sporadic Creutzfeldt-Jakob disease: a case control study. Lancet 1999; 353: 693-697.

14. Will R G. Surveillance of prion diseases in humans. In Baker H, Ridley R (eds) Methods in molecular medicine: prion diseases. pp 119-137. Totowa, NJ: Humana Press, 1996.

15. Kondo K, Kuroiwa Y. A case control study of Creutzfeldt-Jakob disease: association with physical injuries. Ann Neurol 1982; 11:377-381.

16. Davinpour Z, Alter M, Sobel E, Asher D, Gajdusek D C. Creutzfeldt-Jakob disease: possible medical risk factors. Neurology 1985; 35: 1483-1486.

17. Ward H J T, Cousens S N, Smith-Bathgate B et al. Obstacles to conducting epidemiological research in the UK general population. Br Med J 2004; 329: 277-279.

18. Ward H J T, Everington D, Cousens S N et al. Risk factors of variant CreutzfeldtJakob disease: a case control study. Ann Neuro/ 2006; 59: 111-120. 